\title{
Self Medication- A Serious Threat to Society
}

\author{
Mohammed* \\ Kerala University of Health Sciences, India

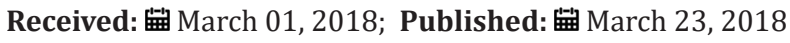 \\ *Corresponding author: Mohammed, Kerala University of Health Sciences, India
}

\begin{abstract}
Self-medication practices involve the consumption of drugs to treat self-diagnosed symptoms or disorders and also include the use of prescribed drugs intermittently or continually for chronic or recurrent ailments or its manifestations. Self-medication is widely practiced as a first-line option in most types of illness and has led to the widespread concern over the irrationality of drug use. The prevalence of such practices is alarmingly high in developing countries where achievement of universal healthcare is far from achieved. The scenario in India, which is stratified by the World Bank into lower-middle income country, is not much different from other developing nation counterparts. Many studies have concluded that people who tend to self-medicate detain care seeking and this in turn can result in paradoxical increase in healthcare cost as a result of the delay in proper diagnosis and therapy. There also arises the problem of drug-interactions and anti-biotic resistance due to lack of guidance from a qualified practitioner who could have mitigated and prevented such instances with his clinical expertise. In the light of these incidences, WHO has emphasized the need to regulate such practices and need to educate the public on the aspects of self-medication?
\end{abstract}

\section{Introduction}

Even though educated and responsible self-medication practices can reduce the unnecessary cost burden in patient and payer perspective and result in overall cost-minimization; some conditions are to be realized for this to be effective [1-3]. These conditions comprise of: the drugs used are indicated for those ailments which are self-recognizable and consumer is educated on the proper drug use and its risks as well as benefits [4,5]. In developing countries, professional health care is relatively expensive and many drugs which are available as prescription drugs in developed countries is available as OTCs; thereby leading to strong reliance on such medications to treat prevalent conditions $[6,7]$. Although as per drug laws relevant to India, self-medication practice is permitted for over-the-counter (OTC) drugs; there is absence of a well-defined list of OTC drugs. Those drugs which do not fall under Schedule $\mathrm{H}$ or G are regarded as OTC and can be procured without the prescription of a registered physician and are consumed as self-medication.

Paradoxically self-medication practices can aggravate the global problem of mounting medical costs due to medication wastage; which is defined as any drug product dispensed by prescription or purchased as an OTC medication that is never fully consumed. Numerous factors are thought to contribute to self-medication and this can vary in a region-specific manner with few of them being lifestyle, easy drug access, socioeconomic factors etc. This questionnaire based study was aimed at assessing the prevalence of self-medication among the students of various professional medical courses in Malappuram district of Kerala and scrutinize the different aspects of such practices.

\section{Methodology}

The study was conducted in Perinthalmanna, which is known as hospital city of Malabar (Northern Kerala). Perinthalmanna houses one medical college, three super speciality hospitals and numerous self-financing institutions offering para-medical courses. The cross-sectional survey was conducted for duration of 5 months from September 2014 to January 2015. 330 undergraduate medical and paramedical students were randomly selected from various institutions and administered a pre-validated questionnaire. The sample size was estimated using Epi-Info 2002 (CI=90\%; level of significance $=5 \%$ ). The questionnaire was structured with multiplechoice options and was designed to capture details on demography, aspects on self-medication such as reason, indications for which commonly used, knowledge, opinion etc. Informed consent was obtained from the participants which detailed the study objectives and provided assurance on the aspects of confidentiality while 
publication or dissemination of results. Data were analysed using SPSS 18 windows version and the results were depicted using figures and percentages. Chi-square test was used to identify association among variables.

\section{Results}

A total of 330 students formed the study sample of which 135 (40.9\%) were males and remaining 195 (59.09\%) were females. Mean age of the sample was determined as 19.4 ( $\mathrm{S} . \mathrm{D}=1.1$ years). $39.70 \%(n=131)$ were Pharmacy students, \% (n=99) were nursing students, $16.06 \%(n=53)$ were M.L.T students and $14.24 \%(n=47)$ were medical students. Of the total study sample, 94.85\% (313) preferred to rely on self-medication to treat minor ailments in contrast to $5.15 \%$ (17) that opted against self-medicating. The difference was found to be extremely significant with $\mathrm{p}<0.0001$. $312(94.5 \%)$ preferred self-medication for themselves and their families, $267(80.91 \%)$ preferred self-medication for their neighbors and $200(60.61 \%)$ preferred the same for friends and relatives. $97.04 \%$ (131) of the male subjects and 93.33\% (182) were found to rely on self-medication. The difference was found to be insignificant with $\mathrm{p}=0.788$ the category of drug for which selfmedication was practiced was stratified with respect to gender and depicted in Table 1.

Table 1: Stratification of self-medication use in each gender.

\begin{tabular}{|c|c|c|c|}
\hline \multicolumn{2}{|c|}{ Male } & Female & p-value \\
\hline Vitamins & $82(62.6 \%)$ & $103(56.59 \%)$ & 0.583 \\
\hline Antibiotics & $63(48.1 \%)$ & $113(62.09 \%)$ & 0.182 \\
\hline Analgesics & $113(86.26 \%)$ & $173(95.05 \%)$ & 0.514 \\
\hline $\begin{array}{c}\text { Nasal } \\
\text { Decongestants }\end{array}$ & $115(87.79 \%)$ & $171(93.95 \%)$ & 0.648 \\
\hline Others & $25(19.1 \%)$ & $47(25.82 \%)$ & 0.314 \\
\hline
\end{tabular}

Headache and nasal congestion (93.94\% each) were cited to be the most common ailment for which self-medication was practiced closely followed fever (92.73\%). Of those who purchased antibiotics, only $66.48 \%$ (117) completed the full course and $76.7 \%$ (135) used a previous prescription to make the purchase. Of those who used prior prescription, it was assessed that the same prescription was used more than 2 times by $72.6 \%$ (98) of the subjects. $11.93 \%$ (21) subjects who used antibiotics contracted adverse effects irrespective of the intensity. Among those who used Vitamins, only 1.62\% (3) suffered adverse effect and among analgesic users, $15.03 \%$ (43) contracted side effects. About 310 (94\%) students prefer self-medication to them and their family members. Knowledge from health magazines, internet, and books were major sources of self-medication. About $45 \%$ were using other system of medicine like Ayurveda as self-medication. Among the subjects, only $12.1 \%$ (38) were unaware that interactions could occur, $13.7 \%$ (43) were unaware of the hazards of increased dose and $36.1 \%$ (113) were unaware of the harm due to improper duration. 85.3\% (267) of the participants who used self-medication believed that they were able to properly diagnose diseases and
$67.29 \%$ (215) considered themselves to be capable of selecting a suitable regimen for therapy.

\section{Discussion}

In developing countries people are not only using nonprescription drugs but also prescription drugs, as self-medication products, without supervision [8]. Self-medication practices are very common among students in Malappuram district. Unfortunately, there are no data available regarding self-medication practices among the general public, which makes it difficult to compare the extent of self-medication among university students with those in the general public [9]. The intensity of the practice of self-medication a matter of embarrassment. MBBS and pharmacy student contributed a major portion of the study population. Pankaj Jain showed that $21.5 \%$ of the actual drug users and $40.6 \%$ of the advocates of self-medication were students [10]. Cold, fever, headache and wounds were treated frequently with the suitable analgesics, antipyretics, antihistamines etc. according to them. The result obtained was found to be similar to a study conducted in Ethiopia.

Vitamins were the most commonly used class of drugs. The consumption of nasal decongestants was found be similar in our study as well in a study conducted abroad. Home remedies such as the application of tooth paste or honey on burned skin and normal saline for throat pain can be appreciated if it has been performed as a first aid before consulting a physician. Gastrointestinal symptoms (gastric pain, acidity, vomiting, diarrhoea) were another option that had been self-treated. Even sleeping pills were consumed illegally; the prevalence is not small and also expected due to high degree of stress in life of medical students [11]. The medical students not only prefer themselves in self-medicating, they also disseminated their drugs to their relatives, friends. Drug consumers were asked of their source of advice/information for self-medication. The knowledge procured for family, relatives and neighbors was a major inspiration for the student for self-medication however; a reduced rate was obtained from a study conducted in Haryana [10]. Social media and internet also lead to this trend. Whereas, doctors were the dominating source of information regarding drugs revealed for another study conducted by Rohit Varma [12]. The ease of accessibility and availability of the medicine had indulged them to such practices [11]. Major reasons of self-medication at student level were time saving, did not need advice from prescriber for minor illness, economic, fear from crowd at clinic [12]. This was one of another reason for self-medication. Most of the students had a trust in allopathic medicine system. The percentage of students favouring Ayurveda were low in contrast to studies in North India [12] $90 \%$ of the drug consumers requested drugs by mentioning the specific name of the drug or drug product, which can be generic or brand. Interestingly, there are some familiar names of brand drug products that dominate over others, and $62.42 \%$ of the respondents requested drugs by mentioning the category of the drug to which it belongs. These categories of drug consumers/patients lend 
themselves to the care of the "pharmacist" in the community pharmacy. It is at this time that the pharmacy professionals have to demonstrate their abilities and expertise of drugs and their role as drug use educators and counselors [10] The rest, $72.6 \%$ were requesting drugs by showing an old sample or package of the drug product by presenting a piece of paper and by describing the physical characteristics such as the colour and/or shape of the drug product.

\section{Conclusion}

Self-medication is practiced by most medical professional course students. Re-orientation of the students to make them completely comprehend the risks and potential harms such as antimicrobial resistance is to be performed and made part of the curriculum in the first year itself.

\section{References}

1. World Health Organization (2000) Guidelines for the regulatory assessment of Medicinal Products for use in self-medication.

2. Sclafer J, Slamet LS, De Visscher G (1997) Appropriateness of selfmedication: method development and testing in urban Indonesia. J Clin Pharm Ther 22(4): 261-272.

3. Angeles-Chimal P, Medina-Flores ML, Molina-Rodriguez JF (1992) Selfmedication in a urban population of Cuernavaca, Morelos. Salud Publica Mex 34(5): 554-561.
4. Deshpande SG, Tiwari R (1997) Self-medication: A growing concern. Indian J Med Sci 51: 93-96.

5. Hughes CM, MCElnay JC, Fleming GF (2001) Benefits and risks of selfmedication. Drug Saf 24(14): 1027-1037.

6. Chang F, Trivedi PK (2003) Economics of self-medication: theory and evidence. Health Economics 12(9): 721-739.

7. Shakoor O, Taylor RB, Behraus RH (1997) Assessment of the incidence of substandard drugs in developing countries. Trop Med Int Health 2(9): 839-845.

8. Abay SM, Amelo W (2010) Assessment of Self-Medication Practices Among Medical, Pharmacy, and Health Science Students in Gondar University, Ethiopia. J Young Pharm 2(3): 306-310.

9. Sawalha AF (2008) A descriptive study of self-medication practices among Palestinian medical and nonmedical university students. Res Soc Admin Pharm 4(2): 164-172.

10. Jain P, Sachan A, Singla RK, Agrawal P (2012) Statistical study on selfmedication pattern in Haryana. India. Indo Global J Pharm Sci 2(1): 21 35.

11. Maier LJ, Liechti ME, Herzig F, Schaub MP (2013) To dope or not to dope: neuroenhancement with prescription drugs and drugs of abuse among Swiss university students. PLoS ONE 8(11): 77967.

12. Verma, Rohit K, Lalit M, Manisha P (2010) Evaluation of self-medication among professional students in North India: proper statutory drug control must be implemented. Evaluation 3(1): 60-64.

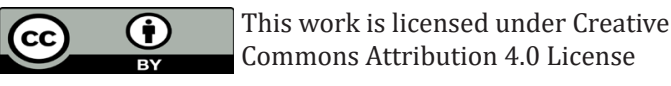

To Submit Your Article Click Here:

Submit Article

DOI: 10.32474/LOJNHC.2018.01.000104

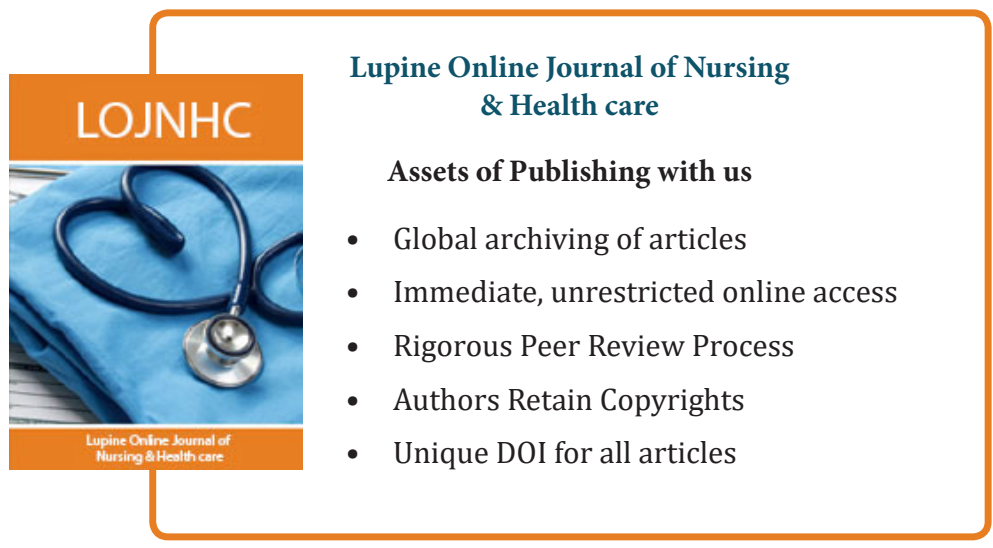

